\title{
Quality of Life in Cancer Patients undergoing Chemotherapy
}

\author{
Ali Dehkordi, ${ }^{1}$ M. Saeed Heydarnejad, ${ }^{2}$ Daryoush Fatehi ${ }^{3}$
}

\section{Abstract}

Objectives: The objective of this study is to describe the quality of life $(\mathrm{QoL})$ in cancer patients with solid tumors and at different chemotherapy (CT) cycles.

Methods: A total of 200 cancer patients were included. With some modification, the European Organization for Research and Treatment of Cancer QoL Questionnaire (EORTC QLQ-C30) was used to measure QoL in the student patients.

Results: There was no correlation between the QoL and variables such as age, sex, marital status, duration of disease, economic conditions, and occupational function. Furthermore, no correlation was found between QoL and the patients' educational level (literate or illiterate). Nevertheless, a significant difference was found between the level of QoL in patients with $\leq 2$ CT cycles and/or with $3-5$ cycles $(p<0.001)$.
Conclusion: This study suggests that encouraging cancer patients to complete a CT course plays an important role in the treatment outcome and the QoL in cancer patients undergoing CT.

From the ${ }^{1}$ Nursing Faculty, Shakrekord Medical University, Shakrekord, Iran ${ }^{2}$ Department of Biology, Shabrekord University, Sharekord, Iran ${ }^{3}$ Dept. of Medical \& Surgical Nursing, Shabrekord University of Medical Sciences, Shahrekord, Iran.

Received: 21 April 2009

Accepted: 15 May 2009

Address correspondence and reprint request to: Dr. Saeed Heydarnejad, Department of Biology, Shabrekord University, Shahrekord, Iran.

E-mail:m_heydarnejad@yahoo.com

Dehkordi A, et al. OMJ. 24, 204-207 (2009); doi:10.5001/omj.2009.40

\section{Introduction}

ccording to the World Health Organization (WHO), quality of life (QoL) is defined as individual perception of life, values, objectives, standards, and interests in the framework of culture. QoL is increasingly being used as a primary outcome measure in studies to evaluate the effectiveness of treatment. ${ }^{1-4}$ Patients generally instead of measuring lipoprotein level, blood pressure, and the electrocardiogram, make decisions about their health care by means of QoL which estimates the effects on outcomes important to themselves. ${ }^{5}$

An increasingly important issue in oncology is to evaluate QoL in cancer patients. ${ }^{6}$ The cancer-specific QoL is related to all stages of the disease. ${ }^{7,8}$ In fact, for all types of cancer patients general QoL instruments can be used to assess the overall impact of patients' health status on their QoL, however hand cancer-specific instruments assess the impact of a specific cancer on QoL. ${ }^{6}$ In some cancer diseases (glioma for instance), QoL has become an important endpoint for treatments comparison in randomized controlled trials so that in these patients clinical studies increasingly incorporate QoL as the endpoint. ${ }^{9}$

The main problems facing long-term cancer survivors are related to social/emotional support, health habits, spiritual/ philosophical view of life, and body image concerns. ${ }^{10-13}$ Many studies have shown good or adequate overall QoL in these cancer patients. However, among long-term survivors, psychosocial issues and physical symptoms such as pain and lymphedema, particularly the adverse effects of systemic adjuvant therapy (chemotherapy) on QoL still persist. ${ }^{11-14}$ The aim of this study is to evaluate the QoL in cancer patients with solid tumors at different chemotherapy cycles.

\section{Methods}

A total of 200 cancer patients were included in this present analysis. The study was conducted in Tehran hospital. Before taking part in the study, subjects filled out a QoL questionnaire, and a formal consent was obtained from all of them. Following Chen et al. 2008, if the following criteria met by the patients, then they were invited to participate: (1) diagnosed with solid tumors, (2) planning to receive chemotherapy, (3) no history of other chronic disease such as diabetic or heart disease, and (4) aged 18 years or older. ${ }^{15}$ With some modification, the European Organization for Research and Treatment of Cancer QoL Questionnaire (EORTC QLQ-C30) was used to measure QoL in the patients. The test consisted of 56 questions and was arranged into five domains (Table 1): (a) physical, role, cognitive, emotional, and social functioning demographic data as well as cancer/treatment information (b) patient's general conditions (c) patient's physical activities (d) social status and occupational function and (e) sleep pattern. 
Table 1: The Scores used to evaluate QoL in Cancer Patients undergoing CT $(\mathrm{N}=200)$.

\begin{tabular}{lccc}
\hline Domain & \multicolumn{3}{c}{ Scores } \\
\cline { 2 - 4 } & $\begin{array}{c}\text { Non } \\
\text { favorable }\end{array}$ & $\begin{array}{c}\text { Fairly } \\
\text { favorable }\end{array}$ & Favorable \\
\hline Patients general conditions & $23-53$ & $54-84$ & $85-115$ \\
Physical activities & $11-25$ & $26-37$ & $38-55$ \\
Social status \& Occupational & $14-32$ & $33-51$ & $52-70$ \\
function & $8-16$ & $17-27$ & $28-40$ \\
\hline Sleep pattern & $56-130$ & $131-206$ & $207-280$ \\
\hline Quality of life & & & \\
\hline
\end{tabular}

With the aid of a nurse and/or a medical student, the questionnaires were filled out during interview. Each question had an equal value and the QoL was quantified as the sum of the scores for all domains. The scores were classified into three categories, namely; favorable, fairly favorable, and favorable. The higher scores on this scale represent a better QoL. The $c^{2}$ test was used to find the correlation of the clinical variables and QoL scores using the SPSS software (version 14). The level of significance was set at $\mathrm{p}<0.05$ for all tests.

\section{Results}

Demographic and cancer/treatment information of the 200 patients are presented in table 2 . The majority of patients (54.5\%) were male, aged $18-75$ years, with a mean age of 46.2 (650\%), unmarried (44\%), primary school graduates (65\%), and had insufficient income (79.5\%). GI (gastrointestinal) cancer at stage III was the most common cancer, accounting for $35-40 \%$ in all the patients.

Table 2: Demographic and Cancer/Treatment in Cancer Patients undergoing CT (N=200)

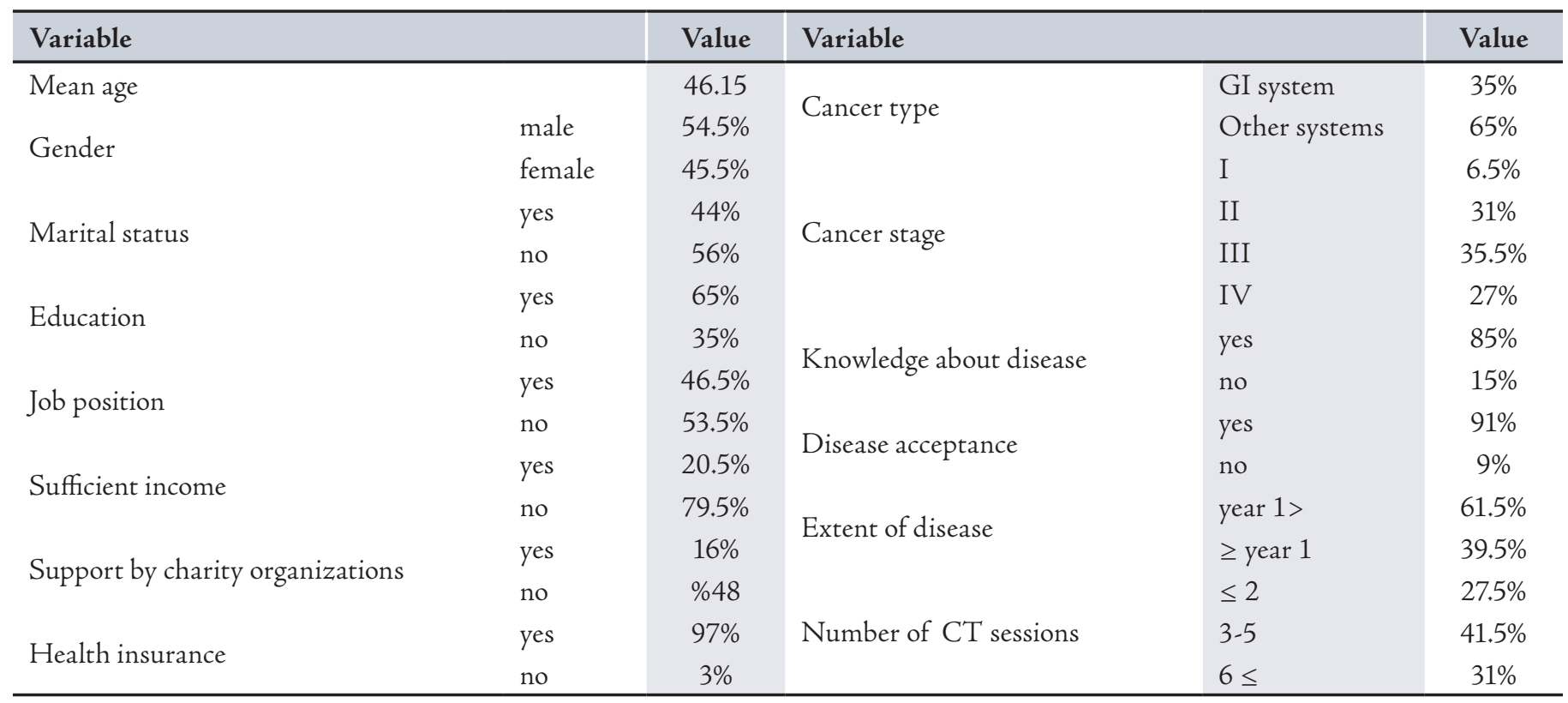

Most of the patients (85\%) were aware of their disease. Findings about QoL in the rest of four domains are depicted in table 3. The most common problems in regard to this category were: fear about future (29\%), thinking about the disease and its consequences (26.5\%), impatience (24\%), and depression (17.5\%). The QoL was fairly favorable in majority (66\%) of the patients. There was no correlation between the QoL and variables such as age, sex, marital status, duration of disease, economic conditions, and occupational function. Furthermore, no correlation was found between QoL and the patients' educational level (literate or illiterate).

Table 3: Frequency and Percentages of Cases in Different Domains regarding QoL in Cancer Patients undergoing CT (N=200)

\begin{tabular}{lccc}
\hline \multirow{2}{*}{ Domains } & \multicolumn{3}{c}{ Number of patients } \\
\cline { 2 - 4 } & Non favorable & Fairly favorable & Favorable \\
\hline Patients general conditions & $(1 \%) 2$ & $(45 \%) 90$ & $(54 \%) 108$ \\
Physical activities & $(3 \%) 6$ & $(74.5 \%) 149$ & $(22.5 \%) 45$ \\
Social status \& Occupational function & $(2 \%) 4$ & $(19.5 \%) 39$ & $(78.5 \%) 157$ \\
Sleep pattern & $(13.5 \%) 27$ & $(28.5 \%) 57$ & $(58 \%) 116$ \\
\hline Quality of life & $(11 \%) 22$ & $(66 \%) 132$ & $(23 \%) 46$ \\
\hline
\end{tabular}


The relationship between QoL and the number of CT cycles is demonstrated in Table 4. As shown, majority (66\%) of the patients had fairly favorable QoL. A strong correlation was found between QoL and number of CT cycles. Nevertheless, a significant difference was found between the level of QoL in patients with $£ 2$ CT cycles and/or with 3-5 cycles $(p<0.001)$. This was also the case for the level of QoL in patients with ${ }^{3} 6$ cycles $(p<0.001)$.

Table 4: Frequency of CT Cycles regarding QoL in Cancer patients undergoing CT (N=200); In Each Case p<0.001

\begin{tabular}{lcccc}
\hline $\begin{array}{l}\text { Number of } \\
\text { CT cycles }\end{array}$ & $\begin{array}{c}\text { Non- } \\
\text { favorable }\end{array}$ & $\begin{array}{c}\text { Quality of life } \\
\text { fairly } \\
\text { favorable }\end{array}$ & favorable & Sum \\
\hline$\leq 2$ & $(16.4 \%) 9$ & $(67.2 \%) 37$ & $(16.4 \%) 9$ & $(27.5 \%) 55$ \\
$3-5$ & $(9.6 \%) 8$ & $(77.1 \%) 64$ & $(13.3 \%) 11$ & $(41.5 \%) 83$ \\
$6 \leq$ & $(8.1 \%) 5$ & $(50 \%) 31$ & $(41.9 \%) 26$ & $(31 \%) 62$ \\
Total & $(11 \%) 22$ & $(66 \%) 132$ & $(23 \%) 46$ & $(100 \%) 200$ \\
\hline
\end{tabular}

\section{Discussion}

QoL refers to "global well-being," including physical, emotional, mental, social, and behavioral components. In the last few years, a number of informative and valid QoL tools have become available to measure health-related QoL. ${ }^{6}$ The most widely applicable instrument to measure the QoL in cancer patients is the EORTC QLQ-C30. Using this method, the current study assessed the QoL in cancer patients undergoing CT. Several studies also support these findings on the influence of CT on good or adequate QoL among the cancer patients undergoing CT.

For instance, Nematollahi showed in patients suffering from lymphatic tumors that there was a positive correlation between $\mathrm{CT}$ and QoL. Likewise, the QoL of African American women with breast cancer was found to be relatively high; cancer recurrence and metastasis to the lymphatic glands had significant effect on the QoL. ${ }^{16}$ It has also been shown that CT had a measurable adverse effect on QoL in women with node-positive operable breast cancer ${ }^{17}$ The results from this current study indicate that CT may improve the QoL in cancer patients.

Currently, QoL has been introduced as an endpoint for treatment comparisons in many cancer types, particularly in advanced stages. ${ }^{18}$ QoL also, as an early indicator of disease progression could help the physician in daily practice to closely monitor the patients. ${ }^{19} \mathrm{QoL}$ may be considered to be the effect of an illness and its treatment as perceived by patients and is modified by factors such as impairments, functional stress, perceptions and social opportunities. ${ }^{3,4}$

As reducing mortality and ensuring optimal health-related QoL are perhaps the main objectives of medical care, this study showed that improvement of QoL in cancer patient can be carried out by means of CT. ${ }^{10}$ In fact, improving QoL is as important as the survival benefit that a pharmacological treatment may provide. However, this is not always the case. For example, Nemati et al. reported that the level of QoL in patients with leukemia was $87.5 \%$ lower than that in the control group. ${ }^{20}$ The differences may be due to different patients' population (sample size or patient age), or cancer types. The current study selected patients (aged ${ }^{3} 18$ years) with various solid tumors while Nemati et al sampled 40 adolescence patients (aged $<18$ years) with leukemia. ${ }^{20}$

In this study, the majority of the patients (68\%) who had completed 3 or more cycles of CT reported a fairly favorable or favorable level of QoL (Table 4). This may show that QoL is directly related to cancer treatment procedure, i.e. CT. Likewise, except for a small group (13.3\%) of the patients reported that their sleep pattern was not favorable, the others had good QoL. This implies that CT can lead to the better sleep pattern in cancer patients. The results are consistent with other studies. For instance, Chen et al, found that QoL in lung cancer patients during the fourth cycles of CT improved slightly over the baseline values; the patients perceived more sleep disturbances during the early cycles of CT. ${ }^{15}$ Similar results have been found in patients suffering from advanced cancer by Mystakidou and from breast cancer by Fortner. ${ }^{21,22}$

The findings of the present study showed that there was no correlation between QoL and age, gender, social status, marriage, and job. Similar results have been reported by Nematollahi, Vedat et al. and Rustøen studies. ${ }^{23-25}$ Furthermore, there was no correlation between the extent of the disease and QoL. In contrast, Rustøen and Holzner in two separate studies found that the extent to which QoL of cancer patients depends on the time elapsed since initial treatment; with an increase in the extent of the disease, a decrease in the QoL was observed. The difference may be due to the duration of the disease; the extent of the disease, in $87 \%$ of the patients from the current study was less than two years whilst it was more than 2 years in Rustøen and Holzner studies. ${ }^{25,26}$

\section{Conclusion}

Cancer is an important health issue influencing QoL. An appropriate treatment which may provide care to the cancer patients is CT. The obtained results here indicate a strong correlation between $\mathrm{QoL}$ and number of CT cycles in cancer patients. Since CT is socially stigmatized in some countries e.g. Iran, encouraging patients to complete a CT course may play an important role in the treatment outcome and the QoL of cancer patients. 


\section{Acknowledgements}

The authors would like to thank the staff members of radiation oncology departments in Tehran University of Medical Sciences. We also appreciate Dr. K. Shafiei for her psychological consults and Mr. A. Mehrban for his statistical consults

\section{References}

1. Guyatt GH, Feeny DH, Patrick DL. Measuring health-related quality of life. Ann Intern Med 1993 Apr;118(8):622-629.

2. Wilson IB, Cleary PD. Linking clinical variables with health-related quality of life. A conceptual model of patient outcomes. JAMA 1995 Jan;273(1):59 65.

3. Spilker B, ed. Quality of Life and Pharmacoeconomics in Clinical Trials. Philadelphia: Lippincott-Raven, 1996:1-1259.

4. Testa MA, Simonson DC. Assesment of quality-of-life outcomes. N Engl J Med 1996 Mar;334(13):835-840.

5. Oldridge N, Gottlieb M, Guyatt G, Jones N, Streiner D, Feeny D. Predictors of health-related quality of life with cardiac rehabilitation after acute myocardial infarction. J Cardiopulm Rehabil 1998 Mar-Apr;18(2):95-103.

6. Boscolo-Rizzo P, Maronato F, Marchiori C, Gava A, Da Mosto MC. Longterm quality of life after total laryngectomy and postoperative radiotherapy versus concurrent chemoradiotherapy for laryngeal preservation. Laryngoscope 2008 Feb;118(2):300-306.

7. Thatcher N, Hopwood P, Anderson H. Improving quality of life in patients with non-small cell lung cancer: research experience with gemcitabine. Eur J Cancer 1997;33:8-13.

8. Hörnquist JO. Quality of life: concept and assessment. Scand J Soc Med 1990;18(1):69-79.

9. Mauer ME, Bottomley A, Taphoorn MJ. Evaluating health-related quality of life and symptom burden in brain tumour patients: instruments for use in experimental trials and clinical practice. Curr Opin Neurol 2008 Dec;21(6):745-753.

10. Casso D, Buist DS, Taplin S. Quality of life of 5-10 year breast cancer survivors diagnosed between age 40 and 49 . Health Qual Life Outcomes 2004 May;2:25.

11. Dorval M, Maunsell E, Deschênes L, Brisson J, Mâsse B. Long-term quality of life after breast cancer: comparison of 8-year survivors with population controls. J Clin Oncol 1998 Feb;16(2):487-494.

12. Ganz PA, Desmond KA, Leedham B, Rowland JH, Meyerowitz BE, Belin TR. Quality of life in long-term, disease-free survivors of breast cancer: a follow-up study. J Natl Cancer Inst 2002 Jan;94(1):39-49.
13. Kornblith AB, Herndon JE II, Weiss RB, Zhang C, Zuckerman EL, Rosenberg $\mathrm{S}$, et al. Long-term adjustment of survivors of early-stage breast carcinoma, 20 years after adjuvant chemotherapy. Cancer 2003 Aug;98(4):679-689.

14. Bower JE, Ganz PA, Desmond KA, Bernaards C, Rowland JH, Meyerowitz BE, et al. Fatigue in long-term breast carcinoma survivors: a longitudinal investigation. Cancer 2006 Feb;106(4):751-758.

15. Chen M-L, Yu C-T, Yang C-H. Sleep disturbances and quality of life in lung cancer patients undergoing chemotherapy. Lung Cancer 2008 Dec;62(3):391400.

16. Northouse LL, Caffey M, Deichelbohrer L, Schmidt L, Guziatek-Trojniak L, West S, et al. The quality of life of African American women with breast cancer. Res Nurs Health 1999 Dec;22(6):449-460.

17. Hürny C, Bernhard J, Coates AS, Castiglione-Gertsch M, Peterson HF, Gelber RD, et al; International Breast Cancer Study Group. Impact of adjuvant therapy on quality of life in women with node-positive operable breast cancer. Lancet 1996 May;347(9011):1279-1284.

18. Bottomley A, Flechtner H, Efficace F, Vanvoorden V, Coens C, Therasse P, et al; European Organisation for Research and Treatment of Cancer (EORTC) Data Center and Quality of Life Group. Health related quality of life outcomes in cancer clinical trials. Eur J Cancer 2005 Aug;41(12):1697-1709.

19. Velikova G, Awad N, Coles-Gale R, Wright EP, Brown JM, Selby PJ. The clinical value of quality of life assessment in oncology practice-a qualitative study of patient and physician views. Psychooncology 2008 Jul;17(7):690698.

20. Nemati M, Alhani F, Zandshahdi R. Quality of life in cancerous adolescences undergoing chemotherapy. 1st congress in quality of life, Tehran, Iran, 2003; Book of Abstracts 25.

21. Mystakidou K, Parpa E, Tsilika E, Pathiaki M, Patiraki E, Galanos A, et al. Sleep quality in advanced cancer patients. J Psychosom Res 2007 May;62(5):527-533.

22. Fortner BV, Stepanski EJ, Wang SC, Kasprowicz S, Durrence HH. Sleep and quality of life in breast cancer patients. J Pain Symptom Manage 2002 Nov;24(5):471-480.

23. Nematollahi A. Quality of life in Iranian women with breast cancer. PhD Thesis, Tehran University of Medical Sciences 2006.

24. Vedat I, Perihan G, Seref K, et al. Improving quality of life in patients with non small lung cancer: research experience with gemeitabine. Eur J Cancer 2001;33:8-13.

25. Rustøen T. Hope and quality of life, two central issues for cancer patients: a theoretical analysis. Cancer Nurs 1995 Oct;18(5):355-361.

26. Holzner B, Kemmler G, Kopp M, Moschen R, Schweigkofler H, Dünser M, et al. Quality of life in breast cancer patients-not enough attention for longterm survivors? Psychosomatics 2001 Mar-Apr;42(2):117-123. 